\title{
ИССЛЕДОВАНИЕ ВЛИЯНИЯ МАКРОЭКОНОМИЧЕСКИХ ИНДИКАТОРОВ НА УРОВЕНЬ ИНВЕСТИЦИОННЫЙ КЛИМАТ В РЕГИОНАХ РОССИИ
}

\author{
(c) 2020 Лисачкина Юлия Сергеевна \\ аспирант \\ Самарский государственный экономический университет, Россия, Самара
}

Внедрение в основных отраслях народного хозяйства России информационных технологий и переход к цифровой экономике требует дополнительных инвестиций, при этом страна переживает последствия кризиса 2014 года и влияние разгорающегося кризиса вызванного пандемией вируca covid-19. В связи с этим тема оценки инвестиционного капитала регионов и влияния на него макроэкономических индикаторов является актуальной в текущий момент времени. Можно выделить цель проводимого исследования, которая выражается в формировании эконометрической модели влияния внутрирегиональных факторов на уровень инвестиций. Решить поставленную цель призваны такие методы научного познания как сравнения, анализ, табличный и графический, корреляционно-регрессионный. К основным результатам проведенного исследования можно отнести следующие: общероссийская динамика инвестиционного процесса, за период 1991-2019 гг., подчиняется параболической функциональной зависимости, таким образом можно утверждать о замедлении темпов роста инвестиций в основной капитал в среднесрочной перспективе; корреляционно-регрессионный анализ выявил наличие двух факторов оказывающих существенное влияние на инвестиционные потоки в регионах, это удельный вес ВДС добывающей промышленности и тип региона по бюджетной классификации; имитационное моделирование дало понимание невозможности безграничного увеличения добывающих производств в структуре экономики и необходимости поиска новых факторов и точек экономического роста. По нашему мнению, отдельные достигнутые результаты проведенного исследования будут полезны региональным органам исполнительным власти в части формирования стратегии экономического развития субъекта на среднесрочную перспективу.

Ключевые слова: пространственная экономика, регионы, инвестиции, эконометрика, влияние, факторы, предсказание.

\section{Введение.}

Рыночная экономика, основанная на потреблении углеводородов, в последние десять лет дает сбои, которые проявляются в финансовых кризисах и снижении темпов роста глобальной экономики. Политики и научные деятели ищут новые драйверы роста, и в последнее время все чаще звучат мнения о цифровизации как возможном направлении дальнейшего развития. Но для осуществления повсеместного внедрения информационных технологий необходимо развитие материально-технической базы промышленности, создание инфраструктуры, разработка и(или) покупка передовых технологий, все это требует значительных инвестиций, которые в современной России являются очень дефицитным ресурсом в связи со стагнацией в экономике, что выливается в дефицит консолидированного бюджета, снижение уровня доходов граждан и падение предпринимательской активности. Все вышесказанное стало причиной подготовки настоящей статьи на основе проведенного исследования направленного на оценку инвестиционного капитала российских регионов и влияние на него макроэкономических индикаторов.

Обращаясь к материалам публикуемых в научной литературе, мы сталкиваемся с рядом публикаций посвященных разрабатываемой нами теме исследования, так в качестве авторов занимавшихся проблематикой инновации можно зазвать: Абрамова М.И. [1], Андреева М.В. [2], Берзон Н.И. [3], Колмыкова Т. С. [5], Красильникова Е.А. [6], Маковкина С.А. [7], Матюгина Э.Г. [8], Муллагалиева И.Ф. [9], Перова В.И. [10], Скоморощенко А.А. [11], Шабанникова Н.Н. [12]. В поле зрения приведенных ученых входили вопросы запуска (активизации) механизма инвертирования в регионе и (или) оценка факторов оказывающих влияние на инвестиционную активность в регионах. Учитывая мнение исследователей, для осуществления анализа взаимосвязей используем систему пока- 
зателей, приведенную на рисунке 1.

Включение в систему фиктивной переменной D продиктовано резким различием уровня экономического развития регионов, по этой же причине включена переменная X4 как сдерживающий фактор развития инвестиционного климата.

Цифровой материал для подготовки проводимого исследования был взят с официального портала Росстата. Для формирования матрицы данных использовались такие издания как: Регионы России, Российский статистический ежегодник, Инвестиции в России.

\section{Результаты исследования.}

На начальном этапе обратится к макроиндикатору, который отражает динамику инвестиций в основной капитал на уровне всей Российской Федерации (рисунок 2).

Как видим, из представленной на рисунке 2 информации, уровни изучаемого временного ряда развиваются по параболической кривой:

$\mathrm{y}^{\prime}=66,73+5,10 \times \mathrm{t}-0,15 \times \mathrm{t}^{2}$, где $\mathrm{R}^{2}=0,58 ;$ $\mathrm{F}(2,25)=17,53$ при $\mathrm{p}<0,05$.

Согласно параметрам приведенной кривой, наблюдается снижение инвестиций в основной капитал с постоянным средним замедлением
0,3\% в год за год. Таким образом, сложившаяся отрицательная тенденция указывает на ускоренное снижение притока инвестиций в национальную экономику.

Далее обратимся к таблице 1 и проанализируем вариацию инвестиций в региональном разрезе.

Сведения, приведенные в таблице 1, указывают на рост инвестиций в 2019 году относительно 2018 г. в пяти федеральных округах из восьми, и снижение в С-ЗФО, ЮФО, УФО. Сложившаяся закономерность обусловлена, прежде всего, стагнацией экономики и как следствие наблюдается недофинансирование регионов-реципиентов из федерального бюджета, падение доходов населения и предпринимательского сектора.

Наибольший инвестиционный поток наблюдается в ЦФО (29,3\% от общероссийского уровня), УФО $(15,1 \%)$ и ПФО $(13,9 \%)$, что объясняется наличием в данных округах развитой промышленности, которая является основным потребителем инвестиций.

Для оценки влияния внутрирегиональных факторов на объем инвестиций на душу населения используем методику корреляционного анализа [13] и рассчитаем значения коэффициентов корреляции Пирсона (таблица 2).

Инвестиции в основной капитал на душу населения (Y), руб.

Валовой региональный продукт на душу населения (X1), тыс. руб.

Валовая добавленная стоимость добывающей промышленности (X2), \%

Валовая добавленная стоимость обрабатывающей промышленности (X3), \%

Государственный долг субъектов РФ (Х4), в \% к доходам консолидированного бюджета

Степень износа основных фондов (X5), \%

$\mathrm{D}$ - фиктивная переменная (1 - если субъект РФ относится к регионамдонорам, 0 - в противном случае) 


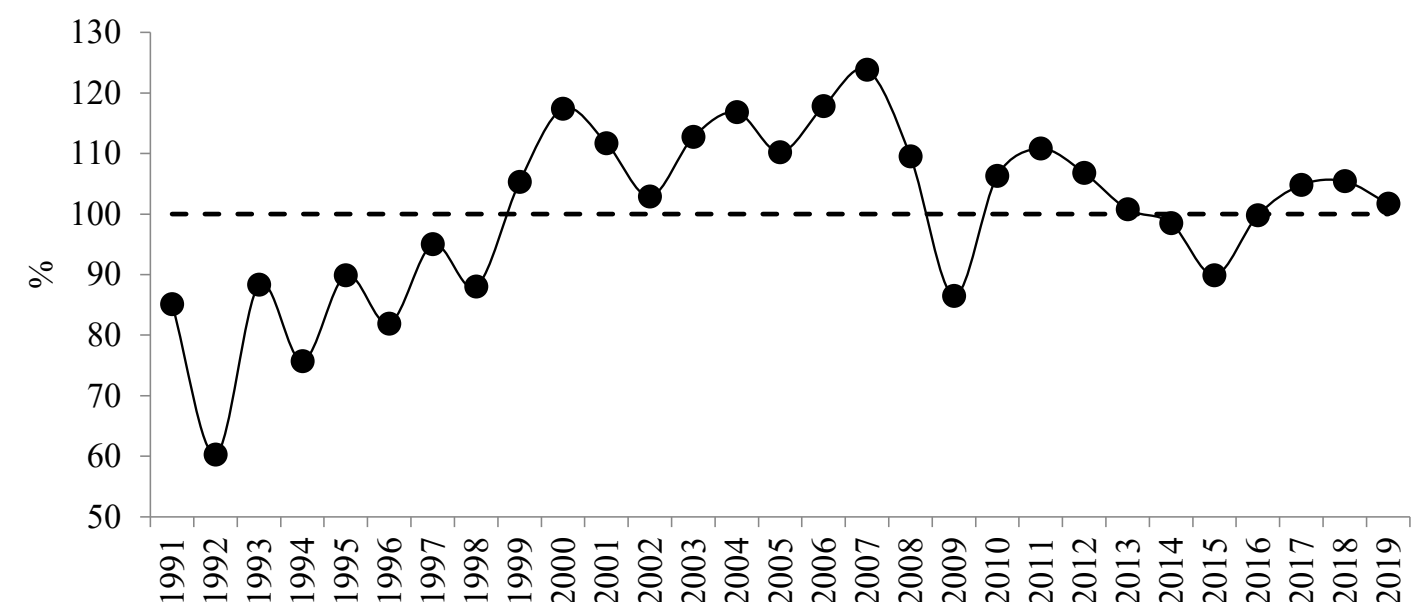

Индексы физического объема инвестиций в основной капитал, в процентах к предыдущему году (в сопоставимых ценах)

Рисунок 2. Динамика изменения уровня инвестиций в основной капитал в России в 1991-2019 гг.,\% (Источник: составлено на основе данных «Российский статистический ежегодник» разных готов издания)

Таблица 1. Динамика инвестиций в основные фонды регионов России, млрд. руб.

\begin{tabular}{|l|c|c|c|c|c|c|c|c|c|}
\hline Регионы России & 2000 & 2005 & 2010 & 2015 & 2016 & 2017 & 2018 & 2019 & В\% к РФ \\
\hline РФ & 1165 & 3611 & 9152 & 13897 & 14749 & 16027 & 17782 & 19319 & 100 \\
\hline ЦФО & 304 & 964 & 2100 & 3578 & 3795 & 4242 & 4998 & 5663 & 29,3 \\
\hline С-ЗФО & 117 & 483 & 1134 & 1437 & 1742 & 1883 & 2309 & 2012 & 10,4 \\
\hline ЮФО & 109 & 245 & 908 & 1296 & 1153 & 1443 & 1456 & 1319 & 6,8 \\
\hline С-КФО & 26 & 93 & 313 & 476 & 486 & 496 & 545 & 611 & 3,2 \\
\hline ПФО & 207 & 609 & 1437 & 2463 & 2438 & 2429 & 2491 & 2690 & 13,9 \\
\hline УФО & 251 & 593 & 1491 & 2358 & 2688 & 2833 & 2967 & 2911 & 15,1 \\
\hline СФО & 88 & 319 & 902 & 1271 & 1326 & 1413 & 1573 & 1789 & 9,3 \\
\hline ДФО & 64 & 303 & 866 & 1018 & 1120 & 1288 & 1444 & 1576 & 8,2 \\
\hline
\end{tabular}

Источник: составлено на основе данных «Регионы России. Социально-экономические показатели» разных годов издания

Таблица 2. Коэффициенты корреляции между переменными оказывающими влияние на инвестиции в регионах России в 2018 г.

\begin{tabular}{|c|c|c|c|c|c|c|}
\hline & $\mathrm{Y}$ & $\mathrm{X} 1$ & $\mathrm{X} 2$ & $\mathrm{X} 3$ & $\mathrm{X} 4$ & $\mathrm{X} 5$ \\
\hline $\mathrm{Y}$ & 1,00 & & & & & \\
\hline $\mathrm{X} 1$ & 0,88 & 1,00 & & & & \\
\hline $\mathrm{X} 2$ & 0,68 & 0,71 & 1,00 & & & \\
\hline $\mathrm{X} 3$ & $-0,32$ & $-0,22$ & $-0,42$ & 1,00 & & 1,00 \\
\hline $\mathrm{X} 4$ & $-0,22$ & $-0,21$ & $-0,09$ & 0,17 & 0,21 & 1,00 \\
\hline $\mathrm{X} 5$ & $-0,10$ & $-0,06$ & 0,08 & 0,24 & & \\
\hline
\end{tabular}


Приведенные в таблице 2 значения коэффициента корреляции указывают на значительное влияние на инвестиции в основные фонды таких факторов как ВРП (X1) и ВДС добывающей промышленности (Х2). При этом между указанными переменными также имеется сильная зависимость $(\mathrm{r}(\mathrm{X} 1 ; \mathrm{X} 2)=0,71)$, т.е. наблюдается проблема мультиколлениарности, а значит, указанные переменные нельзя совместное включать в одно регрессионное уравнения. Также стоит указать на значительное расслоение совокупности субъектов РФ по уровню инвестиций (см. таблица 1) поэтому, в регрессионную модель необходимо ввести фиктивную переменную D. Таким образом, после перебора нескольких вариантов моделей, отличающихся различным набором факторов, на основе значений скорректированного коэффициента детерминации, для итогового анализа, была выбрана модель вида: $\mathrm{Y}=\mathrm{f}(\mathrm{X} 2 ; \mathrm{D})+\mathrm{E}$, результаты оценки параметров которой приведены в таблице 3.

Представленная в таблице 3 эконометрическая модель характеризуется следующими значениями коэффициентов:

- множественный коэффициент корреляции $\mathrm{R}=0,72$, указывает на сильную взаимосвязь между результативной переменной и факторами, вошедшими в модель;

- множественный коэффициент детерминации $\mathrm{R}^{2}=0,51$ свидетельствует о существенной интенсивности связи;

- фактическое значение F-критерия Фишеpa, равное 42,36 , при р<0,00, указывает на статистическую значимость всей модели.

Интерпретация оцененных значений параметров b сводится к следующему:

- значение коэффициента при фиктивной переменной D свидетельствует, что линия регрессии для регионов-доноров на 68614,97 тыс. рублей выше, чем для регионов-реципиентов;

- при росте удельного веса валовой добавленной стоимости добывающей промышленности (X2) на $1 \%$ результативная переменная увеличится на 478,59 рублей на душу населения, при неизменности остальных факторов.

Согласно приведенным выше характеристикам модели, можно констатировать ее статистическую значимость и надежность, поэтому проведем имитационное моделирование, для этого последовательно подставим в модель минимальные, средние и максимальные значения факторов (таблица 4).

Таблица 3. Результаты оценки эконометрической модели влияния факторов на инновационную активность регионов России в 2018 г.

\begin{tabular}{|c|c|c|c|c|c|c|}
\hline Показатели & $\begin{array}{c}\beta \text {-коэффици- } \\
\text { ент }\end{array}$ & SE для $\beta$ & $\begin{array}{c}\text { b-коэффици- } \\
\text { ент }\end{array}$ & SE для b & $\begin{array}{c}\text { t-статистика } \\
\text { Стьюдента }\end{array}$ & р-уровень \\
\hline св. член & - & - & 59755,30 & 9384,91 & 6,37 & 0,00 \\
\hline $\mathrm{D}$ & 0,25 & 0,08 & 68614,97 & 22328,24 & 3,07 & 0,00 \\
\hline $\mathrm{X} 2$ & 0,62 & 0,08 & 3705,87 & 478,59 & 7,74 & 0,00 \\
\hline
\end{tabular}

Источник: рассчитано в табличном редакторе Excel на основе данных «Регионы России. Социальноэкономические показатели». Примечание: SE - стандартная ошибка; параметры модели статистически значимы на $5 \%$ уровне.

Таблица 4. Результаты имитационного моделирования влияния факторов на инвестиции в регионах России

\begin{tabular}{|c|c|c|c|c|}
\hline \multicolumn{2}{|c|}{ Показатели } & $\begin{array}{c}\text { Пессимистический } \\
\text { (мин. значения) }\end{array}$ & $\begin{array}{c}\text { Реалистический } \\
\text { (сред. значения) }\end{array}$ & $\begin{array}{c}\text { Оптимистический } \\
\text { (макс. значения) }\end{array}$ \\
\hline \multirow{3}{*}{$\mathrm{D}=0$} & Х2 & 0,0 & 10,7 & 71,0 \\
\cline { 2 - 5 } & Точечный прогно3 & 59755,3 & 99408,1 & 322871,8 \\
\cline { 2 - 5 } & $-95,0 \%$ CL & 41075,1 & 82786,0 & 384125,1 \\
\hline \multirow{3}{*}{$\mathrm{D}=1$} & +95,0\%CL & 78435,5 & 116030,1 & 391486,7 \\
\cline { 2 - 5 } & Точечный прогно3 & 128370,3 & 168023,0 & 328393,5 \\
\cline { 2 - 5 } & -95,0\%CL & 84185,7 & 127127,2 & 454579,9 \\
\hline \multirow{2}{*}{ Примечание: для оценки имитационных прогнозов использовались возможности пакета STATISTICA } \\
\hline
\end{tabular}


Как следует из приведенной таблицы, по обоим подсовокупностям регионов наибольших результатов можно добиться, увеличив уровень ВДС добывающей промышленности до величины 71\% (соответствует величине Сахалинской области). Но стоит заметить, что данный тип прогноза не соответствует реальности, так как невозможно довести уровень добывающей промышленности до такой величины по причине отсутствия в ряде субъектов РФ полезных ископаемых или истощения их запасов. Соответственно необходимы концептуально новые направления развития регионов [4].

\section{Заключение.}

Подводя итоги проведенного исследования можно сделать следующие выводы:

1) на протяжении периода 2000-2019 гг. наблюдается вариация регионов России по уровню инвестиций в основной капитал, таким образом можно констатировать наличие устойчивого расслоения субъектов РФ, что обусловлено историческими и природно-геологическими особенностями;
2) проведенный корреляционно-регрессионный анализ зависимостей выявил один количественный фактор, определяющий высокий уровень инвестиций в регионах, таковыми является удельный вес ВДС добывающей промышленности, что можно считать логичным в виду сырьевой направленности всей экономики России;

3) имитационное моделирование на основе построенной эконометрической модели, показал, что максимизировать инвестиционный поток возможно увеличив ВДС добывающей промышленности до величины 70-80\%, но подобная структура экономики не возможна (в силу физического отсутствия в регионе полезных ископаемых) и ставит под угрозу экономическую безопасность регионов (вследствие высокой зависимости от мировой конъюнктуры на полезные ископаемые).

Полученные результаты еще раз подчеркивают необходимость диверсификации структуры экономики страны и поиска новых факторов и точек экономического роста.

\section{Библиографический список}

1. Абрамова М. И. Оценка инвестиционного климата региона // Экономическая безопасность и качество. 2019. № 1 (34). С. 38-43.

2. Андреева М.В., Кирик О.Б. Развитие кластерной политики как условие повышения инвестиционной активности в регионе // Инновационная экономика: перспективы развития и совершенствования. 2020. № 4 (46). С. $4-12$.

3. Берзон Н. И. Банковский сектор России: вызовы, проблемы и перспективы // Финансы и бизнес. 2016. № 3. С. $35-46$.

4. Вагин С.Г. Концептуальные пути формирования стратегии развития региональной экономики // Вестник Самарского государственного экономического университета. 2013. № 12 (110). С. 24-27.

5. Колмыкова Т.С., Приходько Ю. Н., Астапенко Е. О. Исследование инвестиционной активности экономики региона // Регион: системы, экономика, управление. 2019. № 3 (46). С. 16-22.

6. Красильникова Е.А., Никишин А. Ф. Интегральные показатели прогнозирования инвестиционной активности регионов // Бизнес. Образование. Право. 2019. № 1 (46). С. 197-201.

7. Маковкина С.А., Воронов Н.Д. Влияние цифровой трансформации на инвестиционную привлекательность региона // Муниципалитет: экономика и управление. 2019. № 4 (29). С. 95-103.

8. Матюгина Э.Г., Клабукова А. А. Инновационная активность и инвестиционная привлекательность региона в аспекте его конкурентоспособности // Экономика: вчера, сегодня, завтра. 2020. Т. 10. № 2-1. С. 300-306.

9. Муллагалиева И.Ф. Повышение инвестиционной активности регионов Российской Федерации // Научный электронный журнал Меридиан. 2020. № 3 (37). С. 54-56.

10. Перова В.И., Папко А.В. Нейросетевой анализ динамики инвестиционной деятельности регионов Российской Федерации // Вестник Нижегородского университета им. Н. И. Лобачевского. Серия: Социальные науки. 2019. № 1 (53). С. 24-32.

11. Скоморощенко А.А. Инструменты стимулирования инвестиционной активности в регионе // Московский экономический журнал. 2019. № 12. С. 29.

12. Шабанникова Н.Н. Анализ и направления повышения инвестиционной активности экономических субъектов региона // Вестник аграрной науки. 2020. № 6 (87). С. 175-183.

13. Эконометрика: учебник / В. Н. Афанасьев, Т. В. Лебедева, Т. В.Леушина, А.П.Цыпин.- Оренбург: ООО ИПК «Университет». 2012.- 402 с. 